\title{
Is it advisable to rehabilitate and release owls with monocular vision?
}

\begin{abstract}
Defective vision is frequent in owls presented to rehabilitation centers. While there is a common consensus that completely blind owls should not be released, there is less certainty when considering owls with monocular vision. To address this issue, surveys of rehabilitation centers and veterinarians were conducted regarding their opinion and experience on the feasibility and ethics of rehabilitating and releasing owls with only one functional eye. Results show conflicting opinions between rehabilitation centers and also veterinarians, with a lack of agreement on what would be best in terms of welfare. This research also compared flight and landing behaviour of four barn owls, of which two had lens opacities to differing degrees and one had only one eye. No significant differences were found between the one-eyed barn owl and the three birds with two eyes in any of the aspects analyzed, namely flight trajectory and time and landing ability on a perch or a handler's glove. Finally, from a literature review and reports from the centers surveyed, successful cases of rehabilitation and release of owls with monocular vision were documented. The findings of our research suggest that new UK guidelines which describe the prerequisites for release of owls with monocular vision should be developed.
\end{abstract}

Keywords: rehabilitation, release, owl, one-eyed bird, survey, flight, landing
Volume 3 Issue I - 2018

\author{
Jennifer Zimmerman, ' Anthony W Sainsbury, ${ }^{2}$ \\ David LWilliams ${ }^{3}$ \\ 'University of London, UK \\ ${ }^{2}$ Zoological Society of London, UK \\ 3University of Cambridge, UK
}

Correspondence: David L Williams, Cambridge Veterinary School, University of Cambridge, Mafdinegley Road, Cambridge, UK, Emaildlw33@cam.ac.uk

Received: October 22, 2017 | Published: January 05, 2018

\section{Introduction}

Ocular diseases in wild owls are commonly presented in rehabilitation centers Labelle et al.,, ${ }^{1}$ often related to trauma Davidson, ${ }^{2}$ which is associated with their frontally directed, large eyes Brooke et al. ${ }^{3}$ Relative to cranial volume avian eyes are approximately 10 times larger than the human globe Waldvogel et al. ${ }^{4}$ Examples on the incidence of ocular disease are shown in Murphy's retrospective study at an owl rehabilitation research centre where from 931 birds of prey admitted, $14.5 \%$ had ocular lesions and unilateral injuries were more common than bilateral Murphy et al. ${ }^{21}$ In the prospective study from the same report $28 \%(n=61)$ of raptors admitted had some form of ocular lesion. In another study, from 128 Tawny owls examined at RSPCA's West Hatch Wildlife Hospital from 2000 to 2002, there were significant ocular lesions in 96 (75\%) of the birds Cousquer. ${ }^{5}$ The high prevalence of eye conditions in owls in rehabilitation centers and the serious implications visual compromise has towards the rehabilitation and release of wild birds of prey, show the importance of ocular diseases as a factor for consideration in the rehabilitation for their release. While there is a common consensus that completely blind owls are not releasable, this is not as certain when considering owls with monocular vision. ${ }^{2,6}$

\section{Binocular vision and depth perception}

One of the main questions when considering birds with monocular vision is whether they can perceive depth appropriately in order to perform the tasks vital for their survival and welfare. Indeed, binocularity allows stereopsis by horizontal disparity and is expected to be important for hunting for prey. Van der Willigen et al. ${ }^{7}$ reported that the principal behavioural purpose of binocular vision in raptors would be the manipulation of the bill for its accurate placement with respect to targets which are close to the animal, and for grabbing or releasing those items. In contrast, Davies \& Green ${ }^{8}$ argue that the control of movement in birds relies more in a range of cues of depth from monocular vision than in stereopsis. They suggest stereopsis is a relatively slow process to achieve accuracy in evaluating depth and results ineffective during the rapid flight movements performed when hunting. In fact, in owls, the actual binocular field is much smaller than expected due to the particular tubular shape of their eyes Martin. ${ }^{9}$ Furthermore, mechanisms for depth perception that can be accomplished with only one eye have also been reported, and includes motion parallax, achieved by moving the head sideto-side while viewing a static object, and looming, the symmetrical expansion of an image or expanding flow fields while approaching an object. Related experimental investigations show that barn owls can use motion parallax to determine depth either with only one or two eyes, ${ }^{7}$ and that pigeon's monocular looming-sensitive cells produced a strong response in the whole receptive field when they saw a directly approaching object with only one eye Wang \& Frost. ${ }^{10}$

\section{Monocularity}

Few articles on ability to cope with monocularity can be found in the literature. Among these, reports from Jager \& Zeigler ${ }^{11}$ and Lee et al. ${ }^{12}$ have shown that pigeons accuracy in grabbing a target, as well as their ability on regulating the braking of the flight and other characteristics of landing, do not vary when changing from binocular to monocular vision. In owls, to the best of our knowledge, only two studies revealed their ability to cope with monocularity. Brown \& Hoffman ${ }^{13}$ rehabilitated and released a one-eyed spotted eagle owl (Bubo africanus) which after nearly five years was found dead after a road traffic accident in the same body condition it had when released, indicating that it had successfully hunted during that period. Hegemann et al..$^{14}$ reports rehabilitation and release of a female eagle owl (Bubo bubo) with one blind eye, and followed up on the animal with a radio-transmitter for over six months, and then visually until a year post-release, during which the bird was able to raise 
offspring. Consistent with these successful cases, two articles Pauli et al. ${ }^{15}$ Davidson ${ }^{6}$ report that chronically monocularly visual owls are presented to rehabilitation centers in good body condition, suggesting that they could in principle hunt and survive avoiding emaciation. From the perspective of animal welfare the current authors consider that, if the birds are able to hunt and maintain their body weight in the wild while monocular, their welfare is highly likely to be better in the wild than confined to a flight aviary.

Owls may represent one of the most resilient raptors when losing one eye. Being nocturnal they may need visual acuity less than a diurnal bird, relying more on other senses such as hearing. Indeed, it has been shown that barn owls (Tyto alba) are able to locate a prey by acoustic location in complete darkness. ${ }^{16,17}$ However, current guidelines for wildlife rehabilitation units from the British Wildlife Rehabilitation Council BWRC ${ }^{18}$ suggest that "particular attention should be paid" to lack of binocularity as a reason for not releasing wild birds; but neither proper instruction nor any specific evidence is provided to support this. In contrast, the International Wildlife Rehabilitation Council and the USA Wildlife Rehabilitators Association Miller ${ }^{19}$ provide guidelines with specific directions for release of visually impaired raptors: "Raptors with limited or questionable vision... need live prey training prior to release. When a raptor has partial or potential vision loss, it is important to test its vision both through its ability to catch live prey and to dodge objects".

Regarding relevant UK legislation, the Wildlife and Countryside Act 1981 is broad and unspecific, allowing each rehabilitation centre to decide if one-eyed owls should be either rehabilitated for release, kept in captivity or euthanized for being unfit to be released. While this is a difficult ethical decision, evidence based information will help to determine the best approach for owl welfare. In order to assist in the development of a new set of UK guidelines for best practice in rehabilitating owls with monocular vision, we carried out:

(i) A survey of rehabilitation centers in England to determine the fate of owls presenting with monocular vision.

(ii) A survey of veterinarians from England and abroad towards their professional opinion on this matter.

(iii) a review of medical records at The Raptor Foundation (Cambridge shire) from the last five years, and

(iv) a comparison of the flight and landing of normal and visually compromised owls held at The Raptor Foundation.

\section{Materials and methods}

\section{Survey of rehabilitation centre staff}

A survey was designed to investigate the outcome of owls with only one functional eye that arrive at rehabilitation centers in England nowadays. The survey consisted on a combination of multiple choice and short answer questions, some of them requesting justifications or more detailed answers. A summary of the questions asked is displayed in Table 1 (full version in Appendix 1) (Table 1). Rehabilitation centers were identified online by searching the terms "raptor", "rehabilitation", "centre", "England" with the search engine Google, and also from the British Wildlife Rehabilitation Council (BWRC. Directory of rehabilitators) and The Barn Owl Trust (The Barn Owl Trust. Barn Owl Directory) web pages. 80 wildlife rehabilitation centers from England were contacted. First, 50 of the centers were contacted by e-mail, giving an explanation of the project with the questionnaire attached. Since, as shown in "Results", this method proved ineffective to collect the information, the centers which did not reply and the remaining 30 were contacted by phone and asked the same questionnaire. If the centre did not answer the call, two more attempts were made at a different time on the same day and on another day. Due to the small number of replies, the data obtained were analyzed using descriptive statistics. The data will be shared with all the centers who participated without revealing the identity of the other centers involved.

Table I Summary of the content of the survey of rehabilitation centres

\section{Survey of rehabilitation centres}

I. Approximately, how many raptors arrive every year at your centre?

2. Approximately, how many owls arrive every year at your centre?

3. Approximately, what percentages of the owls that arrive at your centre have some kind of ocular injury or vision problem?

4. Would a vet assess their sight before rehabilitation?

5. Have you received owls with only one eye or only one functional eye?

If "Yes": - Were those one-eyed owls rehabilitated?

-Were you able to release those one-eyed owls?

6. Do you think one-eyed owls could be rehabilitated for release? Why?

7. Have you ever trained any one-eyed owl to fly? If "Yes": How did it fly?

8. Do you think any specific owl species, after rehabilitation, might cope better with monocularity than any other?

If "Yes": Which and Why?

9. Do you think any owl species might cope worse? If "Yes":Which and Why?

I0.If you did release one-eyed owls: Did you ring any of them? If "Yes": Would you be able to share the number of the ring of the oneeyed owls you released?

I I.Additional comments

\section{Survey of veterinarians}

A survey of veterinarians in England was also conducted, asking their professional opinion towards rehabilitation and release of owls with monocular vision. A summary of the questions asked is included in Table 2 (full version in Appendix 1). 15 veterinarians from England recognized as experienced in avian medicine were contacted by e-mail with the questionnaire attached. In addition, the same set of questions was asked to veterinary ophthalmologists from the UK and abroad through an international veterinary ophthalmology List serve. Due to the small number of replies, the data obtained were also analyzed using descriptive statistics (Table 2).

\section{Raptor Foundation data}

The Raptor Foundation kindly allowed the inspection of their medical archives from the last five years. From each year the total number of raptors received was obtained, as well as the total number of owls, the number of owls with any kind of vision problem, and if they were released or not. For owls with only one functional eye that were released the number of the British Trust for Ornithology (BTO) ring was also acquired and the BTO was called to ascertain if they had any reports on the rings. This data were also analyzed by descriptive statistics. 
Table 2 Summary of the content of the survey of veterinarians

\section{Survey of veterinarians}

I. How often do you receive wild raptor cases?

2. Approximately, what fraction of these cases are wild owls?

3. Approximately, what fraction of these wild owls present some kind of visual impairment or ocular injury?

4. Have you ever received a case of an owl permanently blind in one eye?

5. In your opinion, should a healthy one-eyed owl (free from any other pathology) be rehabilitated for release into the wild?

6. Do you think any specific owl species, after rehabilitation, might cope better with monocularity than any other?

If "Yes": Which and Why?

7. Do you think any owl species might cope worse? If "Yes": Which and Why?

8. Additional comments

\section{Study with barn owls}

To analyze if there are any differences between the flight of owls with monocular vision and normal individuals, the flight of four adult captive barn owls (Tyto alba) that belonged to The Raptor Foundation was studied. Table 3 exhibits basic information from the birds, named A, B, N1, and N2. After examination by direct and indirect ophthalmoscopy and slit lamp bio-microscopy, it was determined that N1 and N2 had no visual impairment, while B had a diffuse opacity in both lenses preventing visualization of the retina (Figure $1 \mathrm{~A} \& 1 \mathrm{~B})$, probably associated with her age (17 years old). Owl A lacked the right eye through previous trauma having the remaining eye completely functional (Figure 1C) (Table 3). Following a series of preliminary trials outdoors and indoors, it was decided to perform the study indoors to avoid the effect of wind and rain on flight, as well as the distraction produced by other birds flying nearby and visitors to the Foundation. The four birds were flown in sessions comprising up to six flights, carried out on five different days. The flights were performed from a perch to a falconer's glove, the owls being lured with food (day-old chicks). Since these owls were already trained for public flying shows, no additional training was needed, avoiding stress to the animals. The owls were called by their name for a maximum of 1 minute to encourage the flight, and the study was concluded for the day when they refused to fly further. Following other reports on the subject Lee et al., ${ }^{12}$ it was decided to record at least 15 flights from each owl (Figure $1 \& 2$ )

Table 3 Basic information of the four barn owls (Tyto alba) studied

\begin{tabular}{lllll}
\hline Animal & Age (Years) & Gender & Weight (G) & Eye condition \\
\hline Owl NI & 2 & Female & 330 & NAD (Nothing abnormal detected) \\
Owl N2 & 8 & Female & 333 & NAD \\
Owl A & 2 & Male & 280 & Right eye missing, Left eye NAD \\
Owl B & 17 & Female & 315 & Diffuse opacity in both lenses
\end{tabular}

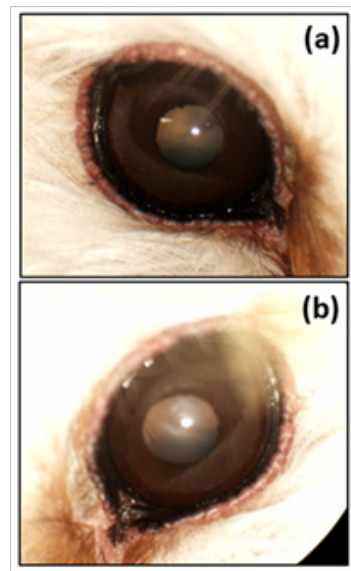

(a)

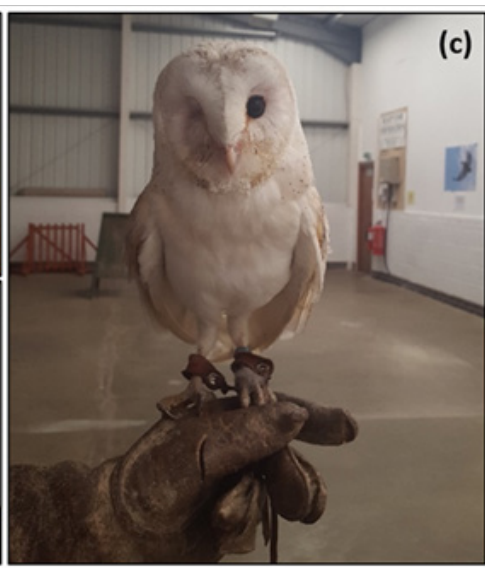

Figure I Barn owls with vision impairments used in flight studies. Owl B right (a) and left (b) eyes showing diffuse opacity in both lenses. (c) Owl A:Adult, male barn owl presenting only one functional eye.

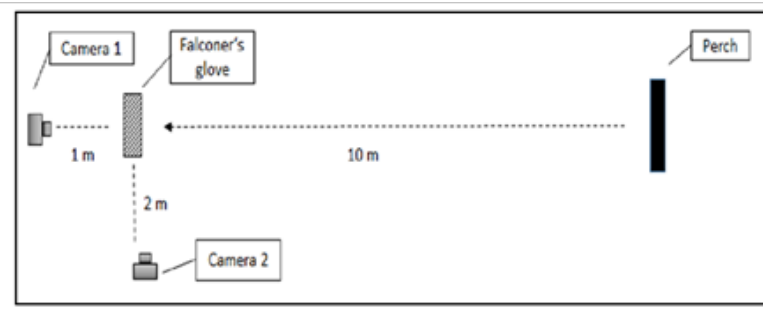

Figure 2 Schematic of the experimental setup for flight studies.
Figure 2 schematises the experimental configuration employed. The perch $(1.1 \mathrm{~m}$ high) was placed $10 \mathrm{~m}$ away from the falconer's glove (1.20 to $1.60 \mathrm{~m}$ high), with one camera (Camera 1) positioned $1 \mathrm{~m}$ behind the falconer, and a second camera (Camera 2) placed at $2 \mathrm{~m}$ from the falconer, on the right side. The side camera (Camera 2) always recorded at a rate of 30 frames per second ( 1 frame $=0.033 \mathrm{~s}$ ), while the front camera (Camera 1) was set (most of the times) at 60 frames per second ( 1 frame $=0.016 \mathrm{~s}$ ) to obtain better time resolution. The long dashed arrow represents the distance between the perch and the falconer's glove, and shows the direction of flight. Camera 1 was positioned $1 \mathrm{~m}$ behind the falconer, approximately $60 \mathrm{~cm}$ above the height of the glove and pointing down at an angle of approximately $45^{\circ}$. Camera 2 was placed at $2 \mathrm{~m}$ on the right side from the falconer, at a height of $1.20 \mathrm{~m}$ and parallel to the floor, so that the cameras axes were perpendicular to each other (Figure 3). The aspects of flight chosen to perform a comparison between different birds are presented in Table 4. The videos recorded by both cameras were interpreted together to perform a reliable appraisal of the trajectory of the flight. Camera 1 videos were convenient for determining the average speed from take-off to landing, while Camera 2 videos were more useful for evaluating the landing. Given the small number of flights and the several measures chosen to carry out the comparison between birds, the data were analyzed with a non-parametric test using KruskalWallis where statistical significance was detected when $p \leq 0.05$ (Table 4) (Figure 4).

\section{Study with tawny owls}

An alternative approach adopted to evaluate and compare flight and landing behaviour of one-eyed and normal owls involved 10 
tawny owls (Strix aluco) from The Raptor Foundation. First, the birds' ocular health was assessed by direct ophthalmoscopy. Three individuals presented with visual impairment: one had lost the left eye with remaining eye without lesions, other had one functional eye with the second eye having a severe corneal opacity, and a third owl was bilaterally blind. Then, the owls' flight behaviour inside their enclosure, where boxes and branches were distributed for perch sites (Figure 5), was characterized. Direct observation was performed for three hours in the morning and two hours in the afternoon on five different days. Video recordings were also obtained during the examinations. In addition, for a night study, two camera traps were attached to opposite sides of the enclosure (at $1.70 \mathrm{~m}$ above the floor) for 17 hours, from $6 \mathrm{pm}$ to $11 \mathrm{am}$ the following day. The cameras were set to the highest sensitivity mode and to take five photos, one per second (the maximum rate that could be set). While each one-eyed owl could be distinguished from the others, it was found that the normal birds were not possible to differentiate between them (colored rings were not visible as legs' feathers covered them most of the time) (Figure 5).

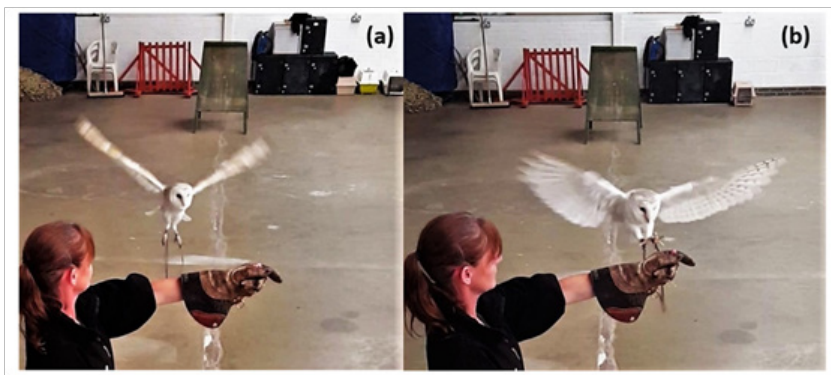

Figure 3 Characteristic moments of the flight. (a) $\vee$ shape adopted at the start of a wing-beat cycle (Owl N2). (b) Braking of the flight with stalled wings and both feet set forward (Owl N2).
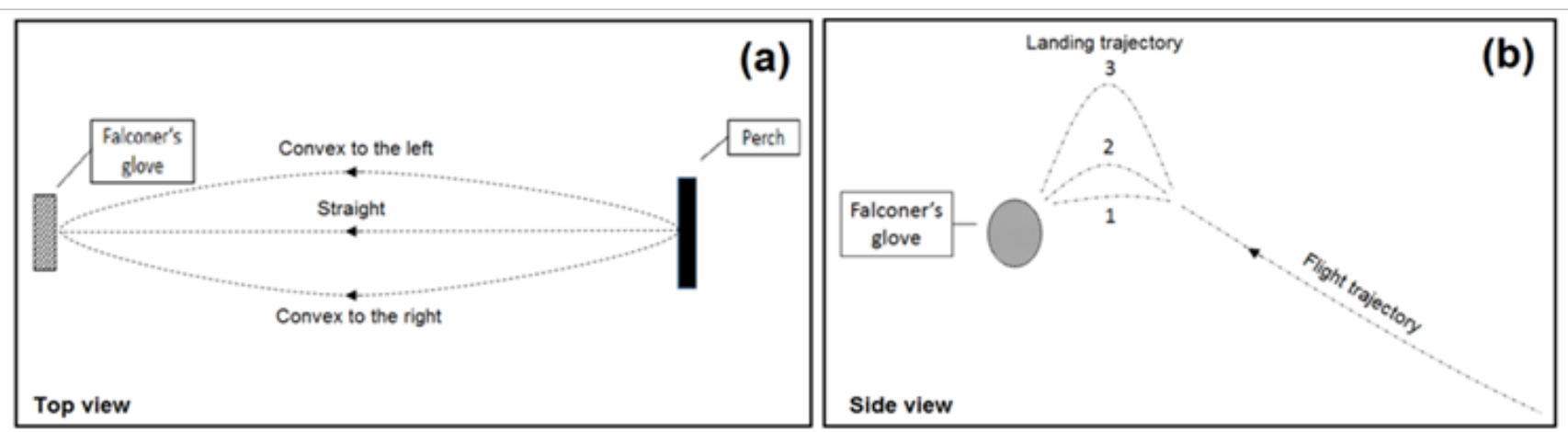

Figure 4 Flight and landing trajectories. (a) Flight paths (top view) include trajectories convex to the left, straight and convex to the right. (b) Landing trajectories (side view) are described as (I) flat, (2) with slight curvature, (3) with pronounced curvature.

Table 4 Aspects considered for flight studies

\begin{tabular}{ll}
\hline Aspect of flight & Description \\
\hline Wing-beat cycle & $\begin{array}{l}\text { From the moment the wings describe a } \\
\text { V shape with the tips at maximum height } \\
\text { (Figure 3A) to the subsequent same position } \\
\text { Position adopted for landing, with stalled } \\
\text { wings and both feet set forward (Figure 3B) }\end{array}$ \\
$\begin{array}{l}\text { Braking position } \\
\text { "Landing I" time }\end{array}$ & $\begin{array}{l}\text { Time elapsed from the start of the final } \\
\text { wing-beat cycle until contact with the glove }\end{array}$ \\
$\begin{array}{l}\text { "Landing 2" time } \\
\text { adopts the braking position until contact } \\
\text { with the glove } \\
\text { from perch to glove } \\
\text { (horizontal plane) }\end{array}$ & $\begin{array}{l}\text { Described as convex to the left, straight or } \\
\text { convex to the right (scheme in Figure 4A) }\end{array}$ \\
$\begin{array}{l}\text { Landing trajectory } \\
\text { (vertical plane) }\end{array}$ & $\begin{array}{l}\text { Described as flat landing (I), with a slight } \\
\text { curvature (2), with a pronounced curvature } \\
\text { (3) (scheme in Figure 4B) }\end{array}$ \\
$\begin{array}{l}\text { Average speed of the } \\
\text { flight }\end{array}$ & $\begin{array}{l}\text { Calculated as: Total distance (I0 m)/Total } \\
\text { time of flight }\end{array}$ \\
$\begin{array}{l}\text { Head movements } \\
\text { before take-off }\end{array}$ & \begin{tabular}{l} 
Described as present or absent \\
\hline
\end{tabular}
\end{tabular}

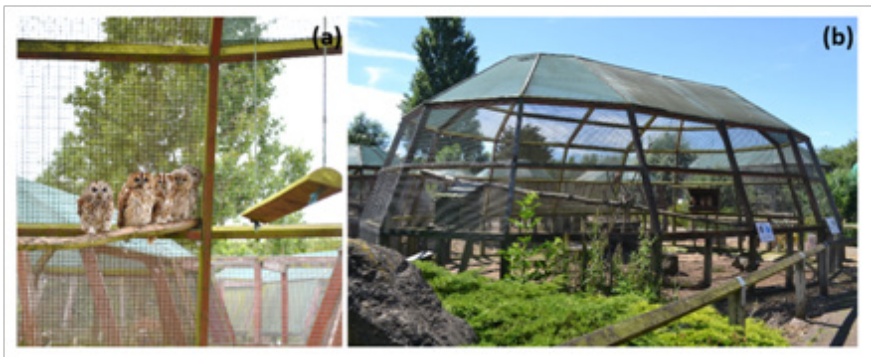

Figure 5 Tawny owls enclosure. Inside (a) and outside (b) views. Dimensions are: $20 \mathrm{~m}$ length, $4 \mathrm{~m}$ tall and $4 \mathrm{~m}$ wide.

Table 5 Number of centres within each category of raptor caseload

\begin{tabular}{lllll}
\hline $\begin{array}{l}\text { Number of raptors } \\
\text { received/year }\end{array}$ & $<50$ & $\mathbf{5 0 - 9 9}$ & $\mathbf{1 0 0 - 1 5 0}$ & $>\mathbf{1 5 0}$ \\
\hline Number of centres & $6(40 \%)$ & $4(27 \%)$ & $3(20 \%)$ & $2(13 \%)$ \\
\hline
\end{tabular}

\section{Results}

\section{Survey of rehabilitation centre staff}

After contacting 50 centers by e-mail, only three replies were obtained. At the same time, out of the 77 centers contacted by phone, 55 answered, and from these, eight were not receiving wild animals any more. From the remaining 47 , the person in charge of rehabilitation of raptors was reached in 37 centers of which 13 answered the survey $(35 \%)$. In the end, 16 replies were obtained in total, however one centre only received one to none owls per year 
and due to this it was excluded from the data analysis. Table 5-10 summarize the information collected. As shown in Tables 5, 10 out of the 15 centers considered received more than 50 raptors per year. At the same time, as deduced from Table 6 , in 12 of the 15 centers at least $50 \%$ of the raptors they received were owls. Excluding one centre that did not reply to the question, as exhibited in Table 7,11 out of the total answered that $10 \%$ or more of the owls that arrived to their centre had some kind of visual impairment or ocular injury (responses varied between 10 to $90 \%$ ). All centers consulted vets before rehabilitation, at least in half the cases (Table 8). 13 of the 15 centers replied that they had received an owl with only one functional eye at least once.

Table 6 Number of centres within each category of owl caseload

\begin{tabular}{lllll}
\hline $\begin{array}{l}\text { Number of owls } \\
\text { received/year }\end{array}$ & $<25$ & $25-49$ & $50-100$ & $>100$ \\
\hline Number of centres & $5(33 \%)$ & $6(40 \%)$ & $2(13 \%)$ & $2(13 \%)$ \\
\hline
\end{tabular}

Table 7 Number of centres within each category of caseload of owls with any kind of vision problem

\begin{tabular}{|c|c|c|c|c|}
\hline $\begin{array}{l}\text { Percentage of owls received } \\
\text { with vision problems }\end{array}$ & $<10 \%$ & $10-24 \%$ & $25-50 \%$ & $>50 \%$ \\
\hline Number of centres & $3(2 \mid \%)$ & $6(43 \%)$ & $3(21 \%)$ & $2(14 \%)$ \\
\hline
\end{tabular}

Table 8 Number of centres consulting vets about the rescued animals

\begin{tabular}{llll}
\hline Consults vets & Always & Sometimes & Never \\
\hline Number of centres & $8(53 \%)$ & $7(47 \%)$ & $0(0 \%)$ \\
\hline
\end{tabular}

Concerning attitudes towards the rehabilitation of owls with monocular vision, as seen in Table 10, they differ substantially. An almost equal number of those surveyed stated that one-eyed owls could be rehabilitated for release (eight centers) compared with those that stated that they could not (seven centers). From the eight that replied positively, seven attempted the rehabilitation of owls with this condition and five were able to accomplish it and performed the release. In addition, the two centers that had the opportunity to train a one-eyed owl confirmed that they were not able to distinguish any difference in the flight from a normal owl. Both centers had a positive opinion towards rehabilitation and release of one-eyed owls. Motives given for negative responses included the lack of evidence indicating that owls with monocular vision would survive in the wild in the same way as normal owls. It was also stated that owls should not be released if they are not fully fit individuals. Moreover, these centers stated that binocularity is necessary not only for hunting, but for a range of other behavioural mechanisms such as direct flight navigation to avoid obstacles, predator avoidance and also mate recognition.

11 centers replied to the question whether any species might cope better with monocularity than another (Table 9). While three answered there should be no difference between species, two centers said barn owls would cope well due to their great hearing, and six agreed on the tawny owls as a species that would manage better than barn owls because they are considered more "robust". Two centers said that the little owl (Athene noctua) would be a good candidate compared to other species. Regarding the five centers that released owls with monocular vision, one provided the ring number of the released animal; however no report of that ring had been received by the BTO. This centre currently has another tawny owl with a chronic ocular lesion and monocular vision. They expressed the opinion that due to the chronic nature of the disease, the animal could hunt before arriving to the centre and survived with that lesion in the wild. Another centre did release a one-eyed little owl which remained alive for at least 3 months after release being recognized at a distance due to a distinctive red tag on its leg. The answers were also analyzed in terms of geographical location to identify if there was any characteristic pattern in the answers, however no such pattern existed and positive and negative answers were given throughout the whole country. The location of the centers is not revealed in order to respect confidentiality.

Table 9 Number of centres answering affirmatively and negatively to six of the questions of the survey

\begin{tabular}{lll}
\hline Question & Answer \\
\hline & Yes & No \\
\hline Received owls with monocular vision? & $13(87 \%)$ & $2(13 \%)$ \\
Rehabilitated owls with monocular vision? & $7(54 \%)$ & $6(45 \%)$ \\
$\begin{array}{l}\text { Released owls with monocular vision? } \\
\text { Believes owls with monocular vision could be } \\
\text { rehabilitated for release }\end{array}$ & $5(62 \%)$ & $8(48 \%)$ \\
$\begin{array}{l}\text { Trained owls with monocular vision to fly } \\
\text { Believes that different species could cope }\end{array}$ & $2(13 \%)$ & $7(47 \%)$ \\
differently with monocularity & $8(73 \%)$ & $3(27 \%)$ \\
\hline
\end{tabular}

Table 10 Two-way frequency table comparing centre's raptor caseload with their opinion towards rehabilitation and release of one-eyed owls

\begin{tabular}{llll}
\hline $\begin{array}{l}\text { Number of raptors } \\
\text { received/year }\end{array}$ & \multicolumn{2}{l}{$\begin{array}{l}\text { Believes one-eyed owls could } \\
\text { be rehabilitated for release }\end{array}$} & Total \\
\hline Yes & No & \\
\hline$<50$ & $3(50 \%)$ & $3(50 \%)$ & 6 \\
$50-99$ & $2(50 \%)$ & $2(50 \%)$ & 4 \\
$100-150$ & $2(67 \%)$ & $1(33 \%)$ & 3 \\
$>150$ & I (50\%) & I (50\%) & 2 \\
Total & $8(53 \%)$ & $7(47 \%)$ & 15 \\
\hline
\end{tabular}

\section{Survey of veterinarians}

Of the 15 veterinarians from England contacted by e-mail, eight replied $(53 \%)$. At the same time, seven veterinary ophthalmologists contacted through the international Listserv answered to the questionnaire. Countries included USA, Germany and Canada. Table 11 summarizes the results obtained from the 15 veterinarians surveyed. As seen from the table, while only four of the eight British veterinarians would advise for the rehabilitation and release of an owl with monocular vision, all seven veterinarians from abroad replied positively towards this matter (Table 11).

\section{Raptor Foundation data}

Clinical records from The Raptor Foundation from the last five years were examined. They show, on average, an admission rate of 146 raptors per year $(\mathrm{sd}=19)$, with an average of 68 owls per year $(\mathrm{sd}=19)$. From the last two years, $88.9 \%$ of the owl's clinical records were available. From these, it was found that the percentage of owls that arrived with any kind of vision problem was $10.3 \%$ (six out of 58 ) in 2015 and $16.4 \%$ (14 out of 79) in 2014. Regarding the records from 
2011-2013, as only $<50 \%$ of clinical records were available at the moment, they were not considered for further analysis. Concerning owls with monocular vision, The Raptor Foundation received one in 2015 which was rehabilitated and released with ring number GV12014. The BTO was contacted regarding this ring, however they did not have any report related to it.

Table II Results of the survey of veterinarians

\begin{tabular}{|c|c|c|c|c|c|}
\hline \multirow[b]{2}{*}{ Veterinarian } & \multirow[b]{2}{*}{ Country } & \multirow[b]{2}{*}{$\begin{array}{l}\text { Approximate Number of } \\
\text { Raptors Attended per Year }\end{array}$} & \multirow[b]{2}{*}{$\begin{array}{l}\text { Approximate Number of } \\
\text { Owls Attended perYear }\end{array}$} & \multicolumn{2}{|c|}{$\begin{array}{l}\text { Would Advise A Rehabilitation Centre to } \\
\text { Rehabilitate an Owl with Only One Functional Eye }\end{array}$} \\
\hline & & & & Yes & No \\
\hline I & England & 189 & 85 & - & $x$ \\
\hline 2 & England & - & - & - & $x$ \\
\hline 3 & England & - & - & - & $x$ \\
\hline 4 & England & $200-300$ & $50-90$ & - & $x$ \\
\hline 5 & England & 500 & 100 & $x$ & - \\
\hline 6 & England & 45 & 30 & $x$ & - \\
\hline 7 & England & - & 20 & $x$ & - \\
\hline 8 & England & - & 6 & $x$ & - \\
\hline 9 & Canada & - & - & $x$ & - \\
\hline 10 & Germany & $150-180$ & - & $x$ & - \\
\hline II & USA & 36 & - & $x$ & - \\
\hline 12 & USA & - & 12 & $x$ & - \\
\hline 13 & USA & - & - & $x$ & - \\
\hline 14 & USA & 24 & 12 & $x$ & - \\
\hline \multirow[t]{3}{*}{15} & USA & - & - & $x$ & - \\
\hline & & & & Total $($ England $)=4$ & Total $($ England $)=4$ \\
\hline & & & & Total $($ Abroad $)=7$ & Total $($ Abroad $)=0$ \\
\hline
\end{tabular}

\section{Barn owls}

The flight and landing behaviour of four barn owls were evaluated. These owls comprised two in normal sight (Owl N1 and Owl N2), one with only one functional eye (Owl A), and Owl B with moderate visual impairment in both eyes from bilateral cataracts. At least 15 flights, of $10 \mathrm{~m}$ length from perch to falconer's glove, were recorded from each owl. As shown in Figure 6A, when considering the four owls, the average flight speed varied significantly $(\mathrm{p}<0.00001)$, with values fluctuating between $4.03 \mathrm{~m} / \mathrm{s}$ and $5.23 \mathrm{~m} / \mathrm{s}$. However, when comparing the one-eyed bird (Owl A) with the normal Owl N2, their flight speeds were found not significantly different $(\mathrm{p}>0.4)$ (Figure 6). Figure 6B shows the "Landing 1" time for each owl; the time elapsed from the start of the final wing-beat cycle until contact with the glove. Even though there was no significant difference between the owls ( $p>0.1$ ), it can be noticed that Owl A was the most constant in time, as shown by the smaller box size, while Owl B was the most variable. Concerning "Landing 2" time (Figure 6C), the time elapsed since the feet of the owl are put forward for landing until contact with the glove, it was also found not significantly different between the owls ( $>0.08)$.

Regarding the flight trajectory, all the owls flew downwards initially and then upwards to the glove. However, while Owl N1's and Owl B's trajectory was almost always convex to the left of the falconer (Figure 7), Owl A and Owl N2 preferred a straight path or slightly convex to the right of the falconer. Each flight finished with the owls decelerating by stalling their wings and moving their feet forward to reach the falconer's glove. Table 12 summarizes the results from all flights for all four birds (Table 12). Figures refer to the numbers of flights corresponding to each kind of trajectory. Types of landing trajectory correspond to those defined in Table 4. Concerning the landing trajectory (results displayed in Table 12), the last wingbeat could describe different shapes and each owl preferred to land in its own way. While Owl B and Owl A usually landed describing a flat silhouette (landing trajectory type 1, as defined in Table 4), presented in Figure 8A, Owl N1 favoured a sharp curve in the last wing-beat (landing trajectory type 3 ) as represented in Figure 8B. Owl N2 most of the times did a slight curve (landing trajectory type 2) but others arrived to the glove in a flat way (Figure 7). Series of pictures describing a flight from Owl N1 at different times t. By comparing with the straight red line, a trajectory convex to the left of the falconer is observed (Figure 8). Series of pictures describing a flat landing from Owl A (a) and a landing with pronounced curvature from Owl N1 (b), at different times t. Red dashed lines show corresponding trajectories. Finally, regarding head movements before take-off (common in barn owls Fux \& Eilam) ${ }^{20}$ none of the owls performed them before flying to the glove. Only Ow1 N2 showed head bobs during a practice before flying to a lamp in the ceiling. 


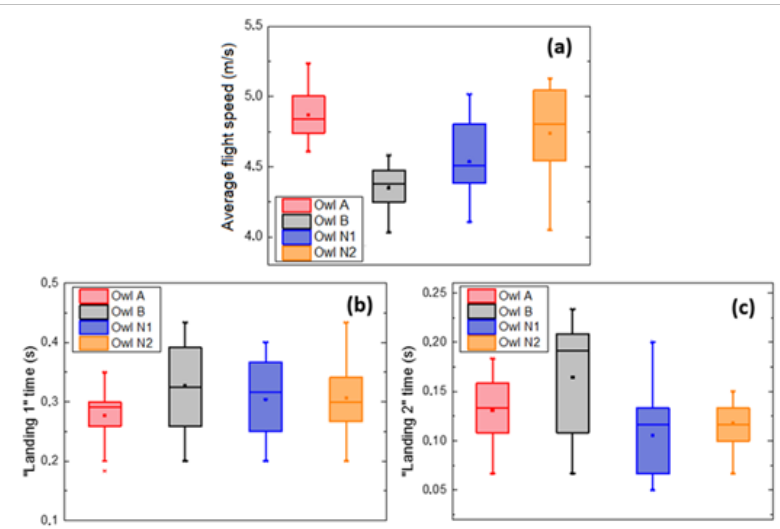

Figure 6 Flight parameters for barn owls. Box plot representation of the average flight speed (a), "Landing I" time (b) and "Landing 2" time (c) for the different owls for several (more than 15) flights.
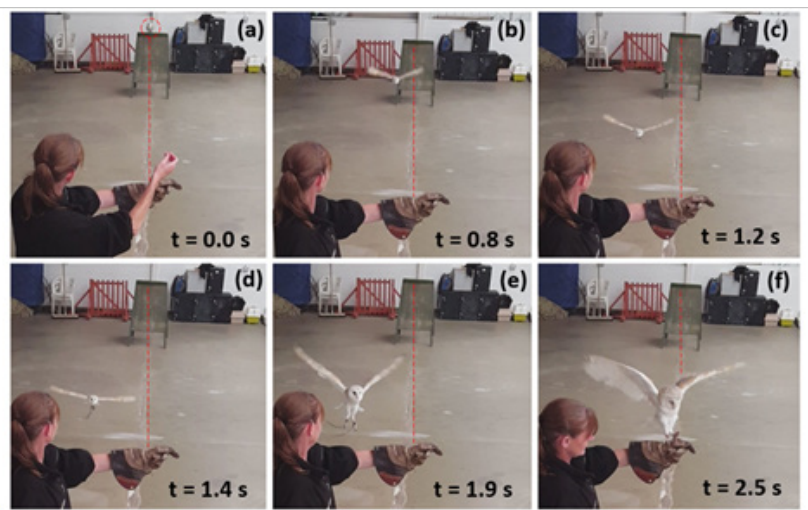

Figure 7 Flight trajectory convex to the left.
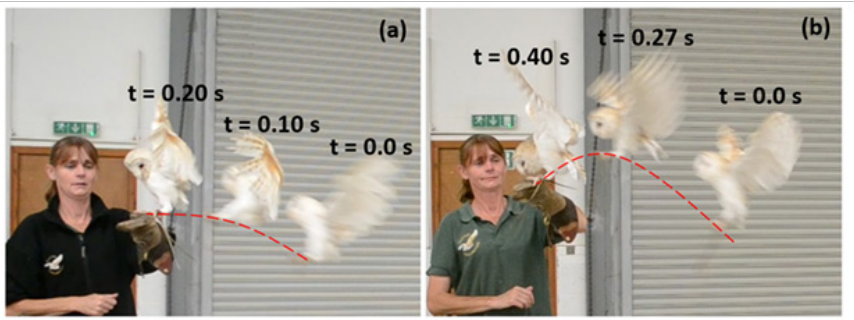

Figure 8 Landing trajectories.

\section{Tawny owls}

From the photographs gathered by the two camera traps (representative pictures in Figure 9) placed in the enclosure of the tawny owls, it was evident that there were more flights at night than during the day. Both cameras registered no flights between $6: 00 \mathrm{pm}$ and 9:30pm (28/06/2016) and from 07:00am to 11:00am (29/06/2016), while from 09:30pm to 04:30am one camera captured 65 flights and the other 90 . However, when the reliability of the cameras was tested by directly observing the birds, six flights were seen which the cameras did not capture, even though the sensitivity was set to maximum. Therefore, it was deduced that the cameras missed many flights, which explains the considerable difference in the numbers of flights that they registered. In addition, the flights that were captured could not be analyzed as the highest setting of one frame per second was not frequent enough to describe any flight. After the camera traps proved ineffective to analyze the flights, it was decided to perform (continuous) video recordings with standard cameras during opening times of the centre. However, after 33 hours of video distributed over six days during daylight, when owls are less likely to fly, only four flights of one-eyed owls could be captured on video, from which the braking of the flight was not easy to define due to the unsuitable angle of the camera. Therefore, it was not possible to compare the flight of the normal and visually compromised tawny owls (Figure 9).
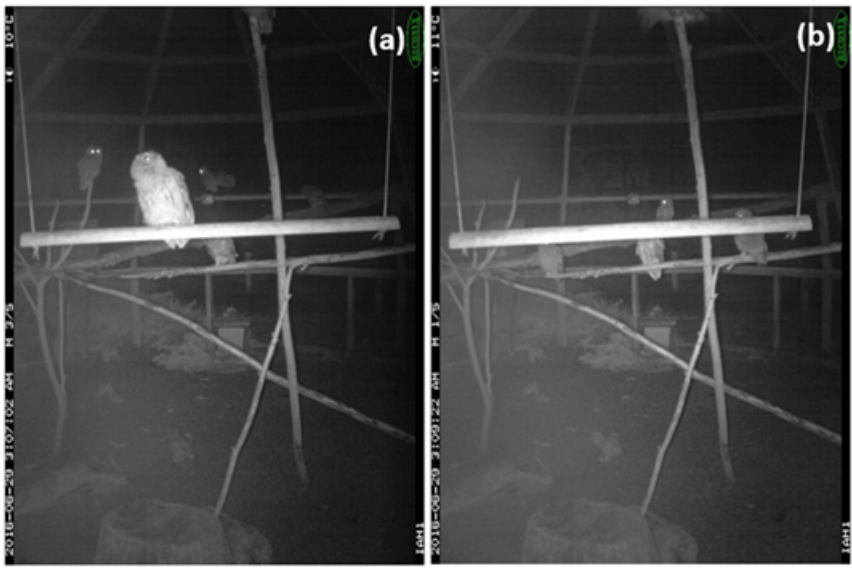

Figure 9 Camera trap images. (a) Camera trap photograph taken at 3:07am on the 29th of June 2016. (b) Camera trap photograph taken two minutes later showing the birds at a different position.

Table 12 Results of flight and landing trajectories for barn owls

\begin{tabular}{lllllll}
\hline \multirow{2}{*}{ Animal } & \multicolumn{2}{l}{ Flight trajectory } & \multicolumn{5}{l}{ Landing trajectory } \\
\cline { 2 - 7 } & Convex to the left & Straight & Convex to the right & Type I & Type 2 & Type 3 \\
\hline Owl A & - & $15(75 \%)$ & $5(25 \%)$ & $19(95 \%)$ & I (5\%) & - \\
Owl B & $15(94 \%)$ & $I(6 \%)$ & - & $11(69 \%)$ & $5(31 \%)$ & - \\
Owl NI & $15(100 \%)$ & - & - & $1(7 \%)$ & $4(27 \%)$ & $10(67 \%)$ \\
Owl N2 & - & $10(67 \%)$ & $5(33 \%)$ & $5(33 \%)$ & $8(53 \%)$ & $2(13 \%)$ \\
\hline
\end{tabular}

\section{Discussion}

The debate over whether visually compromised owls, such as those with only one functional eye, should be rehabilitated is still open. This study used a set of methods to investigate whether monocularly visual owls are suitable for rehabilitation and release. First, a survey was used to document opinion of raptor rehabilitators and veterinarians with expertise in wildlife medicine and ophthalmology. Second, data from a raptor rehabilitation centre were analyzed to determine number of birds received with ocular defects and their fate. Third, the flying behaviour of four barn owls, two normal and two visually compromised was compared. Fourthly, an attempt was made to evaluate the behaviour of a group of tawny owls, some normal and others monocularly visual. 


\section{Surveys}

As presented in Table 7, the percentage of owls arriving at rehabilitation centers with vision problems varied between centers, however, most, including The Raptor Foundation, reported that at least $10 \%$ of the owls received had some kind of visual problem, which is consistent with studies by Murphy et al. ${ }^{21}$ These relatively high percentages of birds with vision problems, combined with the fact that 13 centers received at least one owl with monocular vision, demonstrate the importance of addressing the welfare and ethics of rehabilitating and releasing owls with one functional eye. Moreover, while half of the centers answered they would try to rehabilitate and release these birds, the other half would instead euthanize them see Table 9, with no correlation between opinion and experience of the centre (in terms of number of raptors received per year). Therefore, if an owl with monocular vision is received by one centre it could be rehabilitated for release while if it arrives at another only a few miles away it might be euthanized. Such a situation cannot be good for the welfare of these birds and calls for detailed work to identify whether birds can indeed cope with monocular vision in the wild or not.

One of the reasons given to support the negative position towards rehabilitation was the lack of evidence that owls with monocular vision can survive in the wild. However, there is some evidence shown by two reports in which an eagle owl and a spotted eagle owl with this impairment survived in the wild for at least a year and almost five years, respectively. ${ }^{13}$ This adds to the information shared by one centre in this study that they could keep track of a released one-eyed little owl (Athene noctua) for three months after its release, allowing sufficient time for the bird to produce offspring; this especially relevant for rare species. In line with this, one centre reported it currently has one tawny owl with monocular vision presenting as a chronic ocular lesion. Its state of health other than the ocular lesion showed that the animal could hunt before arriving to the centre, and therefore it could survive with that lesion in the wild, as proposed by Pauli et al. ${ }^{15}$ and Davidson. ${ }^{2}$ In consistency, the two centers who trained one-eyed owls to fly could not identify any difference in the flight of normal and one-eyed owls. Nevertheless, all these are all isolated cases, and thus cannot be directly extrapolated to every owl and every situation. However, such information should be sufficient evidence to show that owls with monocular vision could survive in the wild in particular conditions.

Regarding the survey performed to experienced veterinarians in England, they showed results similar to the ones acquired from the rehabilitation centers, with the same number of positive and negative answers towards the release of owls with only one functional eye. In contrast, the seven veterinary ophthalmologists from other countries, predominantly from the USA, replied all in favour of releasing these animals. Nevertheless, all of the veterinarians in favour, British and from abroad, expressed that the decision would depended on several factors such as age and demonstrated ability to hunt. American veterinarians noted that hunting ability should be tested by evaluating the bird's response when live mice were presented on the floor of the aviary, in agreement with their national guidelines Miller. ${ }^{12}$ Such a test would not be allowed under UK law.

\section{Study with barn owls}

As showed by the results from the surveys, currently, the decision towards the release of one-eyed owls in England depends on particular viewpoints of each centre rather than a defined evidence base. In addition, the guidelines available $\mathrm{BWRC},{ }^{18}$ while being suggestive of a negative position towards the release of owls with monocular vision, are unspecific in terms of any plan of action. Therefore, improvement on UK guidelines is needed, and for this, evidence based information is vital. To contribute with this, we aimed to identify if there was any difference in the flight or landing behaviour in barn owls with compromised vision compared with normal birds.

One of the aspects analyzed was the flight path each bird took to reach the falconer's glove, so as to identify if the one-eyed owl favoured a trajectory due to the lack of the eye. However, no direct correlation was found, suggesting that arriving from the left or right, or performing the last wing beat in a flat or curved profile could be only a matter of the bird's preference. With respect to flight speed, even though the results show a significant difference between the four owls studied, the one-eyed owl, Owl A, was not significantly different from the normal owl N2. Moreover, speed could also be influenced by hunger, age, gender, or even by preference from each owl. Concerning performing head bobs before take-off, a mechanism to perceive depth by motion parallax, its absence from any of the birds in this study could be due to the animals being accustomed to performing similar exercises every day in public displays. This may be supported by the fact that during one practice Owl N2 flew to a lamp and it did head bobs before taking-off. Most importantly, the two characteristic times, "Landing 1" time and "Landing 2" time, chosen to compare owls' ability to assess distance to the glove, were found not significantly different between the birds, which could be a promising result for owls with monocular vision. Nevertheless, several factors have to be taken into consideration before concluding that these birds would cope with monocularity. In this work the flight studies were conducted in a controlled environment, and flying from a perch to a falconer's glove is certainly different from hunting a live prey in the wild. This investigation represents a first approach and further research could better investigate hunting behaviour. For example, by using a dead prey moved by a string, as reported by Shifferman \& Eilan. ${ }^{22}$

\section{Tawny owls}

Unfortunately, as camera traps for night studies proved ineffective, and the tawny owls lacked activity during daylight hours, flight and landing behaviour could not be adequately characterized. This shows the advantages of having trained animals to perform experiments.

\section{Conclusion}

Defective vision is a common affliction in owls that arrive to rehabilitation centers, and many times the impairment is unilateral. Currently, centers must decide what the best procedure is for these birds with a lack of evidence on release or euthanasia. There is no consensus regarding what should be done with owls with monocular vision among English rehabilitation centers and veterinarians, and a need for better guidelines on best practice is evident. There is some evidence that one-eyed owls can survive in the wild for many years, as shown by successful cases from Brown \& Hoffman ${ }^{13}$ and Hegemann et al. ${ }^{14}$ and the report from this study of one little owl with monocular vision remaining alive at least three months after release, and the tawny owl that arrived to the centre with chronic blindness in one eye. Clearly owls with monocular vision can survive in the wild in particular conditions, and therefore possibility towards their release should be seriously considered. Indeed, all surveyed veterinary ophthalmologists from abroad, as well as guidelines from the International Wildlife Rehabilitation Council and the USA Wildlife Rehabilitators Association Miller, ${ }^{19}$ coincide with this view. 
Regarding the flight practices, analyzed landing times were not found to be significantly different between all owls. Furthermore, the speed and landing accuracy of the one-eyed owl was found not significantly different from a normal owl (Owl N2) and also, preferred flight trajectories from these two owls were the same. Therefore, this study shows that the owl with monocular vision, at least in this controlled environment, did not have greater difficulties than a normal owl in assessing distances during flight. All these favourable results suggesting owls could cope with monocular vision and survive in the wild, together with the absence of evidence pointing in the other direction, paves the way towards more realistic experiments that could lead to improved UK guidelines by determining what are the conditions these animals need to survive in the wild with good welfare standards. It might be argued that this study only evaluated a small number of birds and that the conclusions we have drawn from these data are necessarily not as strong as if a larger number of birds had been studied. However we would argue that this study is descriptive, showing that an owl with one eye and ones with lens opacities partially obscuring vision are still able to fly accurately and that this has been adequately documented here even though only a small number of birds were evaluated. ${ }^{23,24}$

\section{Acknowledgements}

None.

\section{Conflict of interest}

The author declares no conflict of interest.

\section{References}

1. Labelle AL, Whittington JK, Breaux CB, et al. Clinical utility of a complete diagnostic protocol for the ocular evaluation of free-living raptors. Vet Ophthalmol. 2012;15(1):5-17.

2. Davidson M. Ocular consequences of trauma in raptors. USA: WB Saunders; 1997. 6:121-130.

3. Brooke MDL, Hanley S, Laughlin SB. The scaling of eye size with body mass in birds. Proceedings of the Royal Society of London B. 1999;266(1417):405-412.

4. Waldvogel JA. The bird's eye view. USA: American Scientist; 1990 $78: 342-353$

5. Cousquer G. Ophthalmological findings in free-living tawny owls (Strix aluco) examined at a wildlife veterinary hospital. Vet Rec. 2005;156(23):734-739.

6. Williams DL, Villavincencio CM, Wilson S. Chronic ocular lesions in tawny owls (Strix aluco) injured by road traffic. Vet Rec. 2006;159(5):148-153.
7. Van der Willigen RF, Frost BJ, Wagner H. Depth generalization from stereo to motion parallax in the owl. J Comp Physiol A Neuroethol Sens Neural Behav Physiol. 2002;187(12):997-1007.

8. Davies MNO, Green PR. Multiple sources of depth information: an ecological approach. Perception and Motor Control in Birds. 1994;339356 .

9. Martin GR. The visual fields of the tawny owl, Strix aluco L. Vision Res. 1984;24(12):1739-1751.

10. Wang Y, Frost BJ. Time to collision is signalled by neurons in the nucleus rotundus of pigeons. Nature. 1992;356:236-238.

11. Jager R, Zeigler HP. Visual field organization and peck localization in the pigeon (Columba livia). Behavioural brain research. 1991;45(1):65-69.

12. Lee DN, Davies MN, Green PR. Visual control of velocity of approach by pigeons when landing. Journal of Experimental Biology. 1993;180:85104.

13. Brown M, Hoffman B. The successful release of a rehabilitated one-eyed owl. Gabar. 2006;17:32.

14. Hegemann A, Hegemann ED, Krone O. Successful rehabilitation and release with a subsequent brood of a one-eyed eagle owl (Bubo bubo). Berl Munch Tierarztl Wochenschr. 2006;120(5-6):183-188.

15. Pauli A, Klauss G, Diehl K, et al. Clinical techniques: considerations for release of raptors with ocular disease. Journal of Exotic Pet Medicine. 2007;16(2):101-103.

16. Payne RS. Acoustic location of prey by barn owls (Tyto alba). Journal of Experimental Biology. 1971;54:535-573.

17. Schwab IR. Double crossed. BMJ. 2003;87(12):1442-1442.

18. British Wildlife Rehabilitation Council. 2016.

19. Minimum Standards for Wildlife Rehabilitation. 4th ed. In: Miller EA, editor. USA: National Wildlife Rehabilitators Association; 2012.

20. Fux M, Eilam D. How barn owls (Tyto alba) visually follow moving voles (Microtus socialis) before attacking them. Physiol Behav. 2009;98(3):359-366.

21. Murphy CJ, Kern TJ, McKeever K, et al. Ocular lesions in free-living raptors. Journal of the American Veterinary Medical Association. 1982;181(11):1302-1304.

22. Shifferman E, Eilam D. Movement and direction of movement of a simulated prey affect the success rate in barn owl Tyto alba attack. Journal of Avian Biology. 2004;35(2):111-116.

23. British Wildlife Rehabilitation Council. 2016.

24. Barn Owl Directory. UK: The Barn Owl Trust. 